\title{
A 13-year real-life study on efficacy, safety and biological effects of Vespula venom immunotherapy
}

\author{
Marcello Albanesi ${ }^{1 *}$, Andrea Nico ${ }^{1}$, Alessandro Sinisi ${ }^{1}$, Lucia Giliberti ${ }^{1}$, Maria Pia Rossi ${ }^{1}$, Margherita Rossini ${ }^{2}$, \\ Georgios Kourtis ${ }^{1}$, Anna Simona Ruccoํ, Filomena Loconte' ${ }^{1}$ Loredana Muolo ${ }^{1}$, Marco Zurlo ${ }^{1}$, Danilo Di Bona ${ }^{1}$, \\ Maria Filomena Caiaffa ${ }^{3}$ and Luigi Macchia ${ }^{1}$
}

\begin{abstract}
Background: Hymenoptera venom immunotherapy (VIT) is a clinically effective treatment. However, little is known about its long-term clinical efficacy and biological effects. Several mechanisms have been proposed to account for VIT efficacy, including reduction of specific IgE and induction of allergen-specific $\lg _{4}$, but the overall picture remains elusive. We investigated Vespula VIT clinical efficacy up to 8 years after discontinuation and the kinetics of Vespulaspecific $\operatorname{lgE}$ and $\operatorname{lgG}_{4}$. Out of 686 consecutive patients we retrospectively selected and analysed a series of 23 patients with Vespula allergy that underwent a 5-year IT course, followed by a prolonged follow-up.

Methods: Clinical efficacy of VIT was assessed as number and severity of reactions to Vespula re-stinging events. The presence of Vespula-specific $\lg \mathrm{E}$ and $\lg _{4}$ was also monitored over time.

Results: During the VIT treatment, patients were protected, reporting no reactions or mild reactions in occasion of re-stinging events. This protection was entirely maintained during the follow-up, up to 8 years. Skin reactivity (reflecting mast cell-bound Vespula-specific lgE) and circulating Vespula-specific lgE levels declined substantially during VIT. Notably, this reduction was maintained over time during the follow-up. Moreover, all the patients were analysed for $\operatorname{lgG}_{4}$. A robust induction of Vespula-specific $\operatorname{lgG}_{4}$ was observed during the VIT course, with a substantial decline during the follow-up.
\end{abstract}

Conclusions: We conclude that Vespula VIT is a clinically effective treatment, which induces long-term protection after discontinuation. The reduction of specific lgE, assessed by skin tests and RAST, closely matches the VIT- induced protection, while the $\operatorname{lgG}_{4}$ induction seems not to be associated with VIT clinical efficacy in the long term.

Keywords: Hymenoptera venom allergy, Allergen immunotherapy, VIT, AIT, Long-term efficacy, Venom-specific IgE, Venom-specific $\operatorname{lgG}_{4}$

\section{Background}

Insect sting allergy is responsible for severe and, sometimes, life-threatening reactions. Venom immunotherapy (VIT) was proven to be effective and safe in patients with venom allergy-induced anaphylaxis $[1,2]$. The

\footnotetext{
*Correspondence: marcello.albanesi@uniba.it

${ }^{1}$ School and Chair of Allergology and Clinical Immunology, Department of Emergency and Organ Transplantation, University of Bari-Aldo Moro, Piazza Giulio Cesare 13, Policlinico, 70124 Bari, Italy

Full list of author information is available at the end of the article
}

clinical efficacy of VIT is commonly defined by a reduction of the severity of the allergic reactions after Hymenoptera stings. In clinical practice, the reduction of both skin reactivity to insect venom and specific IgE levels in serum helps corroborate the assessment of the IT clinical efficacy [3]. Indeed, taken together, these two parameters define the global levels of allergen-specific IgE, as skin reactivity is quantitatively proportional to mast cell bound IgE. Of note, the vast majority of IgE are mast cell bound, whereas serum IgE reflect the minor pool of unbound/circulating IgE. 
Only some reports exist on the long-term clinical efficacy of VIT and the kinetics of bound and unbound IgE after IT discontinuation (Additional file 1: Table S1) [4-10].

In the present study, we investigated, retrospectively, the real-life long-term efficacy of Vespula (Vespula spp.) VIT and its effects of specific IgE and $\mathrm{IgG}_{4}$. Thus, 23 patients (18 men and 5 women), with a history of severe allergic reaction to Vespula sting, underwent Vespula VIT for 5 years, followed by an 8-year follow-up. During the study period, we monitored: (i) allergic reactions to Vespula stings; (ii) performed rigorously standardized quantitative skin testing; (iii) evaluated Vespula-specific IgE levels.

Several mechanisms have been proposed to account for VIT-induced clinical efficacy, including drop of the allergen specific IgE levels and induction of protective $\mathrm{IgG}_{4}$ antibodies [11-14]. In fact, $\mathrm{IgG}_{4}$ are considered protective antibodies for several reasons: (i) among all the IgG subtypes, they have a weak capacity to bind Fcy Receptors and thereby a reduced ability to activate immune cells [15]; (ii) the Fc portion of $\operatorname{IgG}_{4}$ molecule does not fix complement, due to the low affinity for complement factor C1q [16]; (iii) $\mathrm{IgG}_{4}$ are functionally monovalent and unable to form immune complexes. Indeed, $\mathrm{IgG}_{4}$ are dynamic molecules that exchange $\mathrm{Fab}$ arms by swapping heavy-light chain pairs with $\operatorname{IgG}_{4}$ molecules of different specificities $[17,18]$. This results in the production of bispecific antibodies with a substantially decreased capacity for antigen cross-linking $[15,17,18]$.

Thus, we also investigated the kinetics of $\operatorname{IgG}_{4}$ in the 23 patients during the 5-year VIT course and the follow-up.

\section{Methods}

\section{Patients}

Twenty-three patients (18 men, 5 women) with severe Vespula allergy that underwent VIT for 5 years were retrospectively analysed in this study. These patients were monitored for allergic reactions to Vespula stings during 8 additional years, after VIT discontinuation.

\section{Inclusion criteria}

We carefully analysed the clinical files of 686 patients that had access to our Hymenoptera Venom Allergy Service, from 1989 to 2010 and applied a stringent selection process based on the following criteria:

\section{Diagnostic criteria}

a. History of severe adverse reaction to Vespula stinging events: only the patients that had a grade III/ IV [19] reaction to a Vespula stinging events were included in this study. b. Clear recognition of the culprit insect in the entomological display case: only the patients that recognized clearly Vespula as the culprit insect were included in this study.

c. Sensitization to Vespula venom as revealed by both skin test and RAST: patient missing either of these two parameters were excluded from this study.

\section{Therapeutic criteria}

Requirement of 5-year Vespula VIT: patients that underwent either shorter/longer VIT courses or multiple ITs for different Hymenoptera (e.g. Vespula and Polistes) were excluded from this study.

\section{Follow-up criteria}

Requirement of at least one follow-up clinical assessment (at least 3 years after VIT discontinuation), with skin tests execution and serum collection for RAST determination (see below): if one of these determinations was missing the patient was excluded from the study.

\section{Vespula venom IT}

All patients had been treated with Vespula spp. VIT, subcutaneously ( $\mathrm{n}=13$ were from ALK-Abellò VIT supplier, Milan, Italy; $\mathrm{n}=10$ were from Dome Hollister Stier Miles VIT supplier, Spokane, WA, USA). As for the ALK-Abellò VIT, the venom was purified, biologically standardized in Quality Units (SQ-U) and absorbed onto alum hydroxide gel. The maintenance dosage was 100.000 SQ-U. The amount of alum hydroxide contained in the maintenance dose was $1.35 \mathrm{mg}$. The DHS VIT was an aqueous solution of purified Vespula venom. The maintenance dosage was $100 \mu \mathrm{g}$, fully comparable with the ALK-Abellò maintenance dosage [20]. After 10-15 weeks of induction with increasing doses of Vespula venom, the maintenance dose was given every 6 weeks, for 5 years. Adverse reactions to the VIT injections were recorded on the clinical logbook of the patient. In particular, local reactions of less than $10 \mathrm{~cm}$ in diameter were considered mild local reactions. The IT protocols used are summarized in Additional file 2: Table S2 and Additional file 3: Table S3.

The insect-sting challenge test was not performed at the end of the VIT course, due to local ethical policies.

\section{Stings events recording}

Patients were asked to recognize the stinging insect using an entomological display case.

All the patients were interviewed for re-stings and possible related adverse reactions. During VIT course, the interview process was performed every 6 weeks, at every VIT administration. During the follow-up, patients were interviewed approximately 3 and 8 years, respectively, upon VIT discontinuation. 
Vespula re-stinging events were also recorded in the clinical logbook of the patient (along with a few occasional stings by other Hymenoptera). The severity of adverse reaction to stinging events was classified according to Müller [19].

\section{Quantitative skin testing}

Skin tests were performed at baseline and 3 and 5 years after the beginning of VIT. Moreover, the tests were performed at year $3.5 \pm 1.4$ and $8.1 \pm 3.8$ after discontinuation. Skin testing was carried out in a strictly quantitative fashion by two distinct techniques: skin prick testing and intradermal testing, as described [21]. Both techniques were carried out in a single session, sequentially, in a three-step procedure. Thus, the patients were first subjected to skin prick testing, using a $100 \mu \mathrm{g} / \mathrm{ml} \mathrm{Vespula}$ venom solution (see below) and, successively, to intradermal tests with the same allergen at two different tenfold concentrations (viz. 0.1 and $1 \mu \mathrm{g} / \mathrm{ml}$, respectively).

Lyophilized Vespula allergen (Vespula spp.) was supplied by Dome-Hollister-Stier Miles, Spokane, WA, USA, and reconstituted in $1 \%$ albumin saline. Histamine hydrochloride $10 \mathrm{mg} / \mathrm{ml}$ in $50 \%$ glycerol solution (Stallergenes, Antony, France) was used as the positive control in skin prick testing. A $0.002 \mathrm{mg} / \mathrm{ml}$ aqueous solution of the same reagent was used as the positive control in intradermal testing. Saline with $1 \%$ albumin was used as the negative control in both skin prick testing and intradermal testing. Both skin prick tests and intradermal tests were performed on the volar side of the forearms.

As for skin reactivity quantitative assessment, the area of the wheals generated was calculated as described [21]. In order to achieve normalization for inter and intraindividual variations, results were expressed in terms of ratio between the Vespula wheal area and the homologous histamine area, referred to as Skin Index [22].

\section{Serum antibody measurement}

Allergen-specific (Vespula spp.) IgE levels were measured by RAST (ImmunoCAP Thermo Fischer, Milan, Italy) in serum samples collected at baseline, approx. 3 and 6 months, respectively, from starting and, then, yearly during the VIT course. During the follow-up, serum collection took place at the same time-points as for skin testing. The sera were not diluted before the IgE assessment. Results were expressed in mass units (assuming $1 \mathrm{U}=2.4 \mathrm{ng})$.

Vespula-specific $\operatorname{IgG}_{4}$ levels were determined in the above sera using a Vespula $\operatorname{IgG}_{4}$ ELISA kit (Dr. Fooke Laboratories, Neuss, Germany). Thus, Vespula precoated strips were used. The sera of the patients were diluted 1:101, in dilution buffer (supplied), and then added into the correspondent wells. After incubation $\left(1 \mathrm{~h}\right.$ at $\left.37{ }^{\circ} \mathrm{C}\right)$ and extensive washing, $100 \mu \mathrm{l}$ of antihuman $\mathrm{IgG}_{4}$-antibody conjugated with horseradish peroxidase were added, followed by $1 \mathrm{~h}$ incubation at $37^{\circ} \mathrm{C}$. Upon further washing, $100 \mu \mathrm{l}$ of Substrate (also supplied by Dr. Fooke Laboratories) was added and incubated for $10 \mathrm{~min}$, in the dark, at room temperature, revealing the presence of specific $\operatorname{IgG}_{4}$. Upon addition of $50 \mu$ l of stop solution, optical density (O.D.) measurement was carried out using a microplate reader (Biorad, model 450, Milan, Italy), at $\lambda 450 \mathrm{~nm}$. Results were expressed in mass units.

Vespula-specific $\operatorname{IgG}_{4}$ were also determined by an additional experimental approach, based on an in-house adaptation of two different commercially available antibody-revealing tools. Thus, anti-human $\mathrm{IgG}_{4}$ pre-coated 96-well plates (Cayman Chemical Company, Ann Arbor, USA) were used. Upon blocking with $10 \%$ non-fat dried milk, overnight, the wells were incubated at $37{ }^{\circ} \mathrm{C}$ with $50 \mu \mathrm{l}$ of ALLERgen Basic Kit incubation buffer (RADIM, Pomezia, Italy) and $50 \mu \mathrm{l}$ of serum of the patients, for $1 \mathrm{~h}$. Subsequently, after extensive washing, biotinylated Vespula allergen (100 $\mu \mathrm{l}$; also from RADIM) was added, followed by $30 \mathrm{~min}$ incubation at $37{ }^{\circ} \mathrm{C}$. Upon further washing and incubation with streptavidin-conjugated horseradish peroxidase ( $30 \mathrm{~min}$ at $37{ }^{\circ} \mathrm{C}$; RADIM) addition of the substrate (15 $\mathrm{min}$ at room temperature) revealed the presence of specific $\operatorname{IgG}_{4}$. O.D. measurement was carried out as above, at $\lambda 450 \mathrm{~nm}$.

Vespula-specific $\operatorname{IgG}_{4}$ levels were also measured in 20 adult healthy controls (14 female, 6 male; average age $32.4 \pm 8.1$ ) by the commercial kit. Only five of them were studied with the in-house technique.

\section{Statistical analysis}

IgE and $\mathrm{IgG}_{4}$ changes were analysed using one-way Anova with Bonferroni post-test (N.S.: $>0.01$, ${ }^{*} p<0.01$, $* p<0.001)$. Error bars in figures correspond to standard error means. Moreover, the $\operatorname{IgG}_{4}$ results obtained in the patients were analysed against results in healthy controls, using the Student's t Test (N.S. $\mathrm{p}>0.05$, ${ }^{*} p<0.05$ ). Average and standard deviation are used in the text.

\section{Results}

\section{Clinical efficacy and safety of Vespula VIT}

Twenty-three patients were analysed in this retrospective study: 18 men and 5 women (out of a cumulative series of 686 Hymenoptera-allergic patients). All these patients had been diagnosed with Vespula venom allergy and had a clinical history of severe allergic reactions to Vespula stings. Moreover, they had undergone a 5-year Vespula VIT course, with a subsequent prolonged follow-up of up to 8 years. The clinical features of the patients at the time of diagnosis are summarized in Table 1. 
Table 1 Clinical features of the patients enrolled in the study

\begin{tabular}{|c|c|c|c|c|c|c|c|c|}
\hline Patient & Gender & $\begin{array}{l}\text { Severity of } \\
\text { reaction } \\
\text { Pre VIT (accord- } \\
\text { ing to Müller) }\end{array}$ & Age (years) & $\begin{array}{l}\text { VIT duration } \\
\text { (months) }\end{array}$ & $\begin{array}{l}\text { Follow-up } \\
\text { duration } \\
\text { (months) }\end{array}$ & $\begin{array}{l}\text { Total VIT dose } \\
\left(\mathrm{SQ}-\mathrm{U} \times 10^{6}\right)\end{array}$ & $\begin{array}{l}\text { Total VIT dose } \\
\text { (mg) }\end{array}$ & VIT supplier \\
\hline N.G. & M & IV & 60 & 61 & 53 & 4.51 & & Alk \\
\hline T.G. & M & IV & 33 & 58 & 182 & & 5.9 & DHS \\
\hline P.G. & M & IV & 49 & 59 & 122 & & 4.7 & $\mathrm{DHS}$ \\
\hline C.G. & $\mathrm{F}$ & III & 21 & 60 & 184 & & 5.1 & DHS \\
\hline C.G. & M & III & 45 & 59 & 36 & & 5.7 & DHS \\
\hline C.G. & M & III & 35 & 60 & 199 & & 6.5 & DHS \\
\hline D.F.T. & M & IV & 51 & 58 & 103 & 1.82 & & Alk \\
\hline R.F. & M & IV & 44 & 59 & 151 & 2.05 & & Alk \\
\hline G.G. & $\mathrm{F}$ & III & 39 & 73 & 41 & 4.41 & & Alk \\
\hline C.M. & $\mathrm{F}$ & IV & 37 & 61 & 38 & 2.18 & & Alk \\
\hline D.M.S & M & III & 54 & 61 & 36 & 4.44 & & Alk \\
\hline I.N. & M & IV & 54 & 63 & 36 & 2.36 & & Alk \\
\hline A.A. & M & III & 13 & 63 & 62 & 2.11 & & Alk \\
\hline C.M. & M & IV & 39 & 64 & 43 & 2.19 & & Alk \\
\hline D.F. & M & IV & 59 & 64 & 66 & & 5.8 & DHS \\
\hline T.A. & M & IV & 49 & 62 & 28 & & 5.7 & $\mathrm{DHS}$ \\
\hline V.V. & M & IV & 50 & 59 & 51 & & 5.6 & DHS \\
\hline T.A. & M & III & 46 & 60 & 44 & 2.57 & & Alk \\
\hline S.S. & F & III & 29 & 50 & 36 & 3.85 & & Alk \\
\hline M.S. & M & III & 52 & 64 & 56 & 1.71 & & Alk \\
\hline M.A. & $\mathrm{F}$ & III & 33 & 64 & 27 & 2.28 & & Alk \\
\hline V.R. & M & IV & 52 & 62 & 37 & & 6.5 & DHS \\
\hline M.F. & $M$ & IV & 40 & 64 & 31 & & 5.7 & DHS \\
\hline Mean & & & 42.78 & 61.22 & 72.26 & 5.73 & 2.80 & \\
\hline SD & & & 11.81 & 4.02 & 55.37 & 0.54 & 1.07 & \\
\hline
\end{tabular}

DHS Dome Hollister Stier, ALK ALK-Abellò

At first, we evaluated clinical efficacy of Vespula VIT. The single stinging events were assessed and the symptoms associated with their severity. During the VIT course, patients were carefully interviewed every 6 weeks, at every VIT administration. Likewise, during the follow-up, patients were personally interviewed at two different time points after VIT discontinuation (approximatively 3 and 8 years). During the VIT course, 16 patients $(69.6 \%)$ were stung by a Vespula, with a total of 44 stinging events, evenly distributed over time (on average, 8.8 stinging events/year \pm 5.4 ). Particularly, during the first year of VIT there were 13 stinging events in 8 patients. All the stung patients were protected. In fact, none of these events led to a major systemic reaction (grade IV according to Müller) [19], 8 events (18.2\%) were followed by a mild to moderate systemic reaction (grade II-III), whereas 36 events $(81.8 \%)$ were either followed by a local reaction (grade I) or were completely asymptomatic (Fig. 1a).
During the follow-up, 14 patients $(60.8 \%)$ were stung by Vespula, with a total of 46 stings. Importantly, the vast majority of these stinging events were either followed by a local reaction or asymptomatic (43 events, 93.5\%), whereas only three stings (6.5\%) were followed by a moderate systemic reaction (grade III; Fig. 1a). The severity of the adverse reaction towards re-stinging events decreased over time in the same allergic individuals undergoing Vespula IT and subjected to multiple stings and this protection was maintained long after VIT discontinuation (data not shown).

Furthermore, we assessed the safety of VIT. To this aim, we monitored the possible adverse reactions to the subcutaneous VIT injections. During the 5-year VIT course, 998 injections in total were given. Of these, 990 (99.2\%) were followed by no adverse reaction of any kinds, whereas eight injections $(0.8 \%)$ were followed by a local immediate reaction. None of the injections was followed by a systemic anaphylactic reaction (Fig. 1b). 

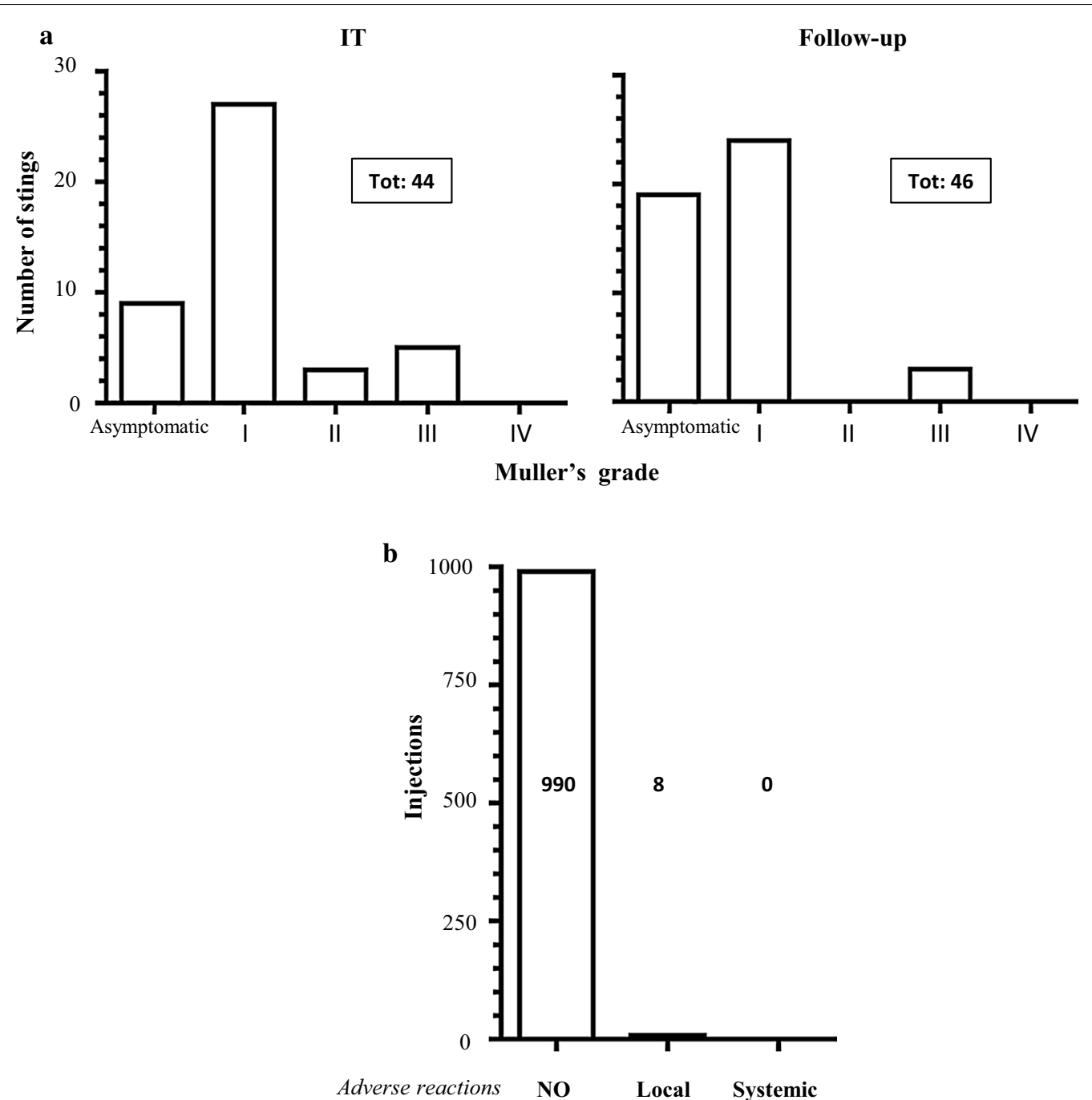

Fig. 1 Clinical efficacy and safety of VIT. a Re-stinging events were counted and classified according Müller's grade, during VIT course (left panel) and follow-up (right panel). b Analysis of adverse reactions to injections performed during VIT course

\section{Kinetics of Vespula-specific lgE}

IgE interact via the Fc portion with FceRI, expressed on different cell types, in particular mast cells. FceRI is a high affinity receptor that has a dissociation constant $\left(\mathrm{K}_{\mathrm{d}}\right)$ of $10^{-9}$ [23]. As a consequence, the vast majority of $\operatorname{IgE}$ is linked to tissue resident mast cells (i.e. the bound pool). The remaining part of IgE (i.e. the much lesser unbound pool) circulates in plasma [24]. In allergic subjects, the amount of specific IgE bound on mast cell surface may be assessed through quantitative skin testing $[21,25]$. The amount of unbound IgE may be evaluated by RAST [26]. Thus, using these techniques, we evaluated the kinetics of both bound and unbound Vespula-specific IgE, during the VIT course and the follow-up.
As shown in Fig. 2a, during the VIT course, the skin reactivity (reflecting the bound pool of Vespula-specific IgE) steadily declined over time, with a $62.5 \%$ reduction after 5 years (Skin Index from $0.8 \pm 0.6$ to $0.3 \pm 0.3$ ). This reduction was essentially maintained throughout the follow-up.

In contrast, soon after the beginning, VIT induced a significant increase in Vespula-specific circulating IgE (from $20.8 \times 10^{3} \pm 27.0 \times 10^{3} \mathrm{ng} / \mathrm{ml}$ to $42.1 \times 10^{3} \pm 44.8 \times 10^{3}$ $\mathrm{ng} / \mathrm{ml} ; \mathrm{p}<0.001$ ), peaking approximately 3 months after VIT initiation. After this initial transient increase, circulating IgE levels steadily declined over time, reaching an average value of $17.1 \times 10^{3} \pm 20.2 \times 10^{3} \mathrm{ng} / \mathrm{ml}$, at the end of the treatment, as expected [27]. During the follow-up 


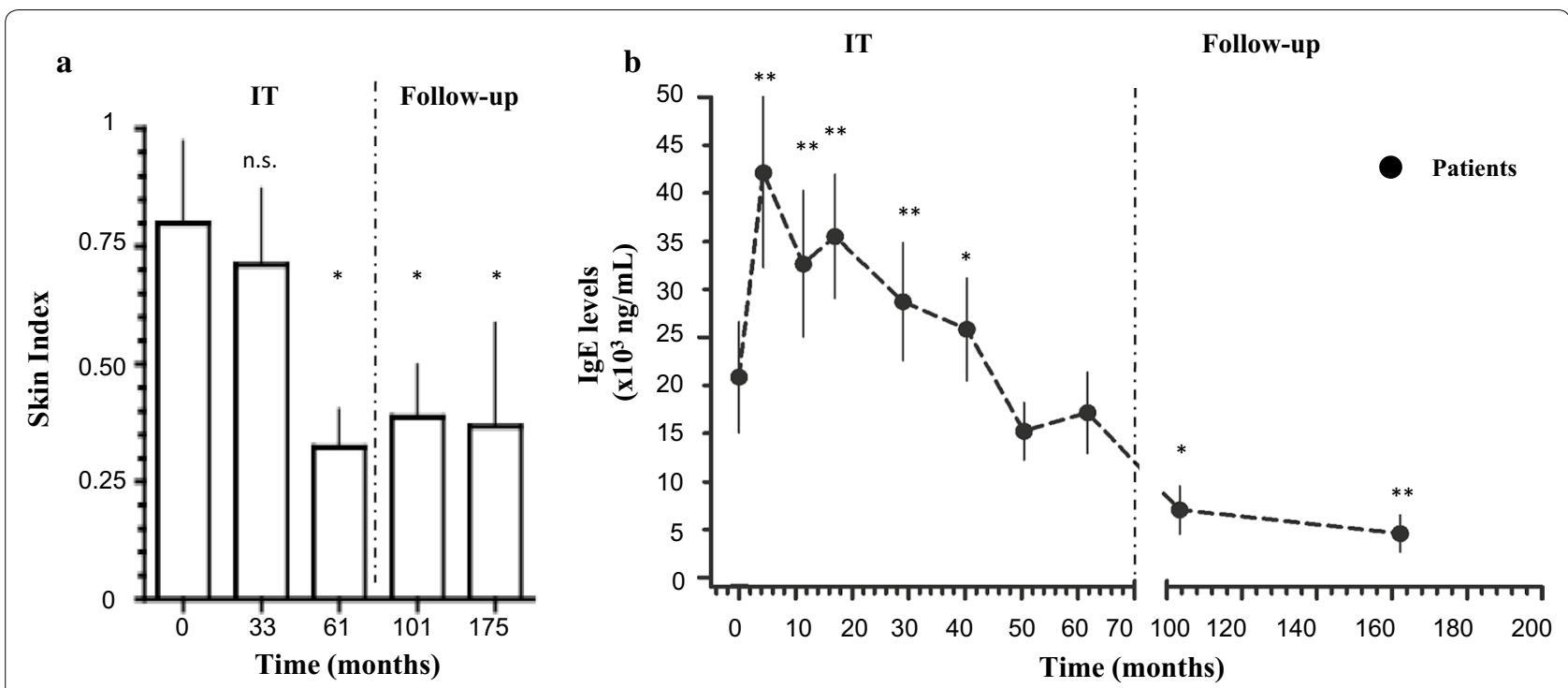

Fig. 2 Kinetics of Vespula-specific IgE. a Kinetics of the bound pool of Vespula-specific lgE assessed by quantitative intradermal skin testing, at the indicated time-points (months). Skin Index represents the ratio between the area of the allergen wheal and the area of the exogenous histamine reference wheal. Intradermal skin tests were performed with a $0.1 \mathrm{\mu g} / \mathrm{ml}$ concentration of Vespula venom. Time-points on $x$-axis are averages of individual time-point. b Kinetics of circulating pool of Vespula-specific lgE measured using RAST, at the indicated time-points (months; averages of individual time-points). Results are expressed as mean \pm SEM. Statistical significance against baseline time-point was calculated by one-way Anova with Bonferroni post-test (N.S.: $>0.01,{ }^{*} p<0.01,{ }^{* *} p<0.001$ ). Dashed vertical line separates the VIT course from the follow-up

we observed a further drop of the circulating Vespulaspecific IgE levels, down to $4.5 \times 10^{3} \pm 6.1 \times 10^{3} \mathrm{ng} / \mathrm{ml}$ (71.1\% reduction; Fig. $2 \mathrm{~b})$. No differences in the kinetics of mast-cell bound and circulating IgE were observed when patients treated with ALK-Abellò and patients treated with DHS VIT were compared with each other (Additional file 4: Figure S1A).

\section{Kinetics of Vespula-specific $\lg \mathrm{G}_{4}$}

We assessed the Vespula-specific $\operatorname{IgG}_{4}$ levels, at the same time-points as for circulating IgE. Interestingly, in all these patients an increase of Vespula-specific $\mathrm{IgG}_{4}$ was detected during the VIT course (from $293.2 \pm 292.8 \mathrm{ng}$ / $\mathrm{ml}$ at baseline to $718.2 \pm 527.2 \mathrm{ng} / \mathrm{ml}$ at 29 months, during the VIT course, to $630.5 \pm 475.5 \mathrm{ng} / \mathrm{ml}$ at the end of the IT course). The induction of $\operatorname{IgG}_{4}$ was not maintained over time, during the follow-up. Indeed, a drop in the $\mathrm{IgG}_{4}$ levels after VIT discontinuation was observed, down to $328.3 \pm 260.1 \mathrm{ng} / \mathrm{ml}$ and $323.9 \pm 259.2 \mathrm{ng} / \mathrm{ml}$ at 103 and 162 months, respectively (Fig. 3a).

No differences in the kinetics Vespula-specific $\mathrm{IgG}_{4}$ were observed when patients treated with ALK-Abellò and patients treated with DHS VIT were compared with each other (Additional file 4: Figure S1B).

In order to validate the technical approach used to assess the $\mathrm{IgG}_{4}$ levels, we developed an in-house $\mathrm{IgG}_{4}$ assay, based on the adaptation of two different commercially available antibody-revealing tools. Thus, in 6 out of the 23, patients we evaluated the $\operatorname{IgG}_{4}$ levels using two different assays.

The set of results obtained were comparable with each other (Fig. 3b).

It is also worth noticing that Vespula-specific $\mathrm{IgG}_{4}$ levels in healthy controls at the baseline were significantly lower compared with the 23 patients.

\section{Discussion}

It is widely accepted that Vespula VIT induces protection from stings in allergic patients during VIT and after discontinuation. In 2004, Golden and Colleagues monitored children with allergy to insect stings that had undergone VIT [8]. Importantly, they demonstrated that VIT in children leads to a significantly lower risk of systemic reactions to stings, up to 20 years after the treatment is stopped, suggesting that clinical efficacy is long lasting [8]. In 2008, Hafner et al. performed a long-term survey in adult patients who had previously discontinued VIT. The majority of the patients reported that the symptoms experienced with stinging events after VIT discontinuation were milder than symptoms before VIT, suggesting again long-term efficacy [9]. Moreover, Pravettoni and co-workers, analysing a series of 232 patients, found that $35.2 \%$ of the patients who could be monitored (159) reported at least one field sting up to 10 years after VIT discontinuation. None of them suffered from any systemic reactions [28]. 

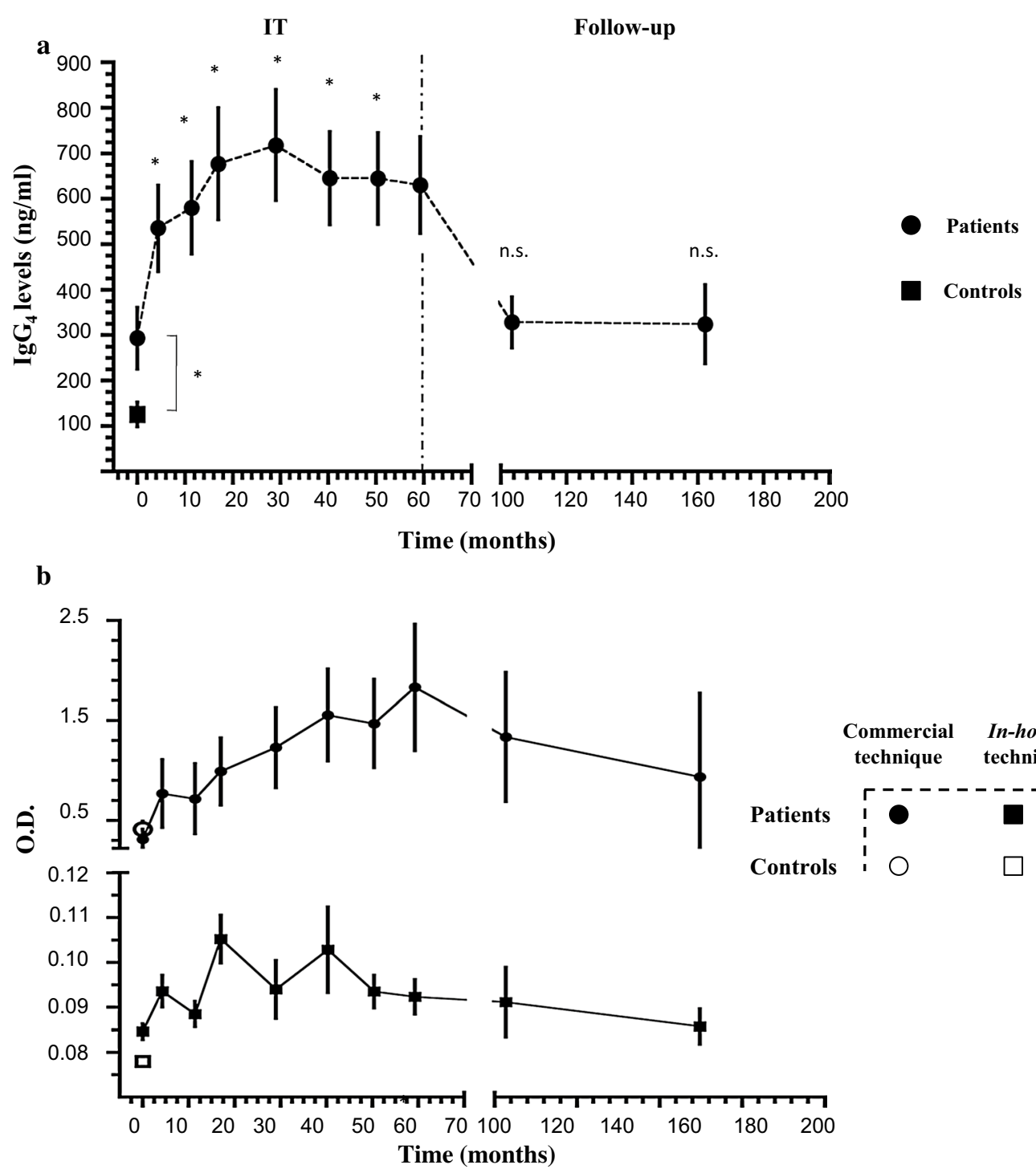

Fig. 3 Kinetics of Vespula-specific $\operatorname{lgG}_{4}$. a Kinetics of serum Vespula-specific $\lg _{4}$ measured using commercial ELISA kit at the indicated time-points, in months (averages of individual time-points). $\mathrm{N}=23$ patients and 20 healthy controls. Statistical significance against baseline time-point was calculated by one-way Anova with Bonferroni post-test (N.S.: $>0.01,{ }^{*} p<0.01,{ }^{* *} p<0.001$ ). Dashed vertical line separates the VIT course from the follow-up. b Comparison of measurement (O.D.) obtained with the $\operatorname{lgG}_{4}$ commercial kit versus the in-house technique at the indicated time-points, in months (averages of individual time-points). $\mathrm{N}=6$ patients and five healthy controls. Results are expressed as mean \pm SEM

However, few reports exists on VIT clinical efficacy long after discontinuation in adult patients (Additional file 1: Table S1) and most of them rely on data obtained through mail questionnaires sent to the patients after VIT discontinuation or telephone interviews.

Moreover, near-all these studies present some points of relative weakness, mostly because of considerable heterogeneity at different levels (Additional file 1: Table S1): (i) age of the patients, (ii) duration of the IT, (iii) type(s) of venom(s) administered during VIT (e.g. honeybee, Vespula) and (iv) VIT supplier used.
As for the age of patients, the outcome of the immune response is age-related [29]. Therefore, the final outcome of VIT and its long-term efficacy may vary accordingly. Moreover for duration of VIT, some of the studies on long-term efficacy included patients that underwent variable periods of VIT (from 3 to 5 years). Nonetheless, such difference might influence the outcome of the long-term immunological memory and therefore the extent of the long-term protection. Moreover, Hymenoptera venoms are, to some extent, cross-reactive and this could introduce biases in the assessment of VIT outcomes, when 
two therapies are given together. As an example, Vespula antigen 5 (Ves v 5), one of the major Vespula allergen, contains 204 amino acids residues and shares $60 \%$ of sequence identity with Polistes dominulus antigen 5 (Pol d 5) [30]. Therefore, patients undergoing VIT for these two different venoms could possibly develop a longer and more robust protection compared to patients receiving VIT for a single venom.

Finally, in near-all the reports present in the literature the VIT supplier is not declared. This latter point appears to be particularly relevant as Hymenoptera venoms comprise a complex mixture of different proteins that might all contribute to sensitization. Indeed, in vespid venom three main allergens have been described: Phospholipase A1, Hyaluronidase and Antigen 5 [31]. Importantly, the purification process of the venom extracts may vary between manufacturers [32,33] and, therefore, the final quality and composition of the venom extracts might not be fully comparable. Thus, a different outcome in the final immune response might be obtained using different venom preparations.

In our work, we analysed a homogenous group of adult patients (mean age of 42.8 years \pm 11.8 ) that underwent Vespula VIT only, for almost exactly 5 years (on average 61.2 months \pm 4.0 ). After VIT discontinuation, we monitored all the patients over a prolonged followup (Table 1). Moreover, in our study, 11 patients were treated with DHS and 12 with ALK-Abellò ITs. It has to be noticed that in all the patients nearly the same induction/maintenance protocol was used (Additional file 2: Table S2 and Additional file 3: Table S3) and the final dose of venom received was fully comparable, regardless of the suppliers [20]. Interestingly, no differences were observed in terms of clinical protection in the patient treated with VIT of either of the two suppliers (data not shown). Moreover, both DHS and ALK-Abellò ITs induced comparable effects on circulating Vespula-specific IgE and $\mathrm{IgG}_{4}$ (Additional file 4: Figure S1A, B). This latter observation indirectly confirms that the immunogenicity of the VIT used was also similar.

We demonstrated that Vespula VIT confers a robust protection not only during the VIT course, but also long after its discontinuation. Indeed, during the follow-up, $60 \%$ of the patients were re-stung, of whom $93 \%$ were minimally symptomatic or asymptomatic and none of the patients needed to resume Vespula VIT, which suggests that a 5-year IT course is possibly protective and can be recommended, at least in Vespula allergic patients. In order to evaluate clinical efficacy of Vespula VIT the patients in our study were interviewed for stinging events at each single administration during VIT and at two time (at least) points during the follow-up. In the case of a sting, they were asked to recognize the culprit insect at every interview, using an entomologic display case. It has to be noticed that Vespula appears to be correctly recognized in $72.3 \%$ of the cases from Vespula allergic patients [34]. This rather stringent approach represents a novelty.

Moreover, aside clinical efficacy, we also evaluated the biological effects of Vespula VIT. Indeed, as shown in Additional file 1: Table S1, few reports assessed the long-term biological effects of venom IT. Even though a drop of circulating specific IgE titres was sometimes observed in up to $70 \%$ of the patients undergoing VIT [35], only little information is present in the literature on the kinetics of venom-specific IgE long after treatment discontinuation.

As it is known, IgE molecules have a unique immunological behaviour. Indeed, at the steady state, the vast majority of IgE is bound on the surface of the mast cells via the interaction with FceRI, a high affinity receptor, able to bind a single IgE molecule with $\mathrm{K}_{\mathrm{d}}$ of $10^{-9}$ [23]. The remaining smaller pool of IgE circulates in plasma in unbound form. Therefore, in our study, we monitored both bound and unbound pools of Vespula-specific IgE.

On the one hand, changes in the bound pool of IgE were assessed with skin testing, performed in a strictly quantitative fashion. Data of this kind are particularly scarce in the context of long-term studies. Indeed, skin test results might be influenced by several factors such as circadian rhythm and technical expertise of the operator performing skin testing, thus demanding methodological rigour. Moreover, in order to render our data comparable with each other, we put emphasis on achieving normalization of the results. To this aim, we expressed this parameter by a Skin Index, previously defined as the ratio between the area of the wheal generated by the Vespula allergen and the area of the wheal generated by exogenous histamine [21]. Remarkably, we observed a robust reduction of skin reactivity (62.5\% reduction after 5 years of VIT) after VIT that was maintained throughout the follow-up (Fig. 2a). To our knowledge, few works have so far analysed skin reactivity/variation in mast cell-bound specific IgE in a strictly quantitative fashion at different time points. In particular, before VIT, during the VIT course and long after VIT discontinuation.

On the other hand, the unbound pool of Vespula specific IgE was assessed by RAST. In line with other reports [36, 37], we observed a transient increase of circulating Vespula-specific IgE early after VIT initiation, peaking at 3 months (Fig. 2b). This time-point corresponds to the end of the IT induction phase, during which the allergen is administered weekly, at increasing doses. Thus, the increase in Vespula-specific IgE titres might be explained by the presence in allergic subjects of memory IgE B cells. These cells are able to differentiate into 
IgE-producing plasma cells upon allergen encounter $[38,39]$. Interestingly, during this initial phase of VIT, the patients are already protected towards re-stinging events. Indeed, during the first year of VIT course, we observed 13 re-stinging events (in 8 patients) that were either asymptomatic or followed by a reaction of grade I of the Müller scale. This observation suggests that the clinical protection is already present early during the VIT course, despite the high Vespula-specific IgE levels. This initial increase was followed by a progressive and steady decline during the maintenance period. Surprisingly, we observed a persistent and further reduction of circulating IgE levels long after VIT discontinuation. This latter data suggest the induction of immunological changes, possibly inducing tolerance, resulting in the decline of specific IgE levels (Even though mast-cell bound Vespula-specific IgE levels seemed not to decline further during the follow-up) (Fig. 2a, b).

The cross-comparison between the clinical data, the quantitative skin test analysis and the data on circulating Vespula-specific IgE seems to suggest that the drop of Vespula-specific IgE levels might be mechanistically related to the long-term efficacy of VIT. As a consequence, based on our data, one can propose to use the venom-specific IgE levels (assessed after discontinuation) as a biomarker for long-term VIT clinical efficacy, at least in Vespula allergy.

However, the precise immunological mechanisms underlying VIT efficacy are probably more diverse and complex and still unclear [40-43]. Particularly, VIT has been shown to induce a rise in specific IgG $_{4}$ levels. It is well known that a regular and persistent exposure to an antigen is able to induce $\operatorname{IgG}_{4}$ antibodies [44]. As mentioned above, $\operatorname{IgG}_{4}$ should be considered anti-inflammatory antibodies. Indeed, $\mathrm{IgG}_{4}$ are dynamic molecule that behave as monovalent antibodies and therefore cannot form immune complexes [17]. Moreover IgG due to their poor binding capacity to both complement and Fc $\gamma$ Rs, activate only weakly Fc-dependent immune mechanisms, such as antibody dependent cytotoxicity or the complement cascade $[15,16]$. However, even though $\mathrm{IgG}_{4}$ have been previously proposed as a contributing factor to the clinical efficacy of VIT $[45,46]$, no reports have analysed the changes in the $\mathrm{IgG}_{4}$ levels long-after VIT discontinuation, so far (Additional file 1: Table S1).

Thus, we evaluated changes in the levels of Vespulaspecific $\mathrm{IgG}_{4}$ throughout VIT and follow-up in the 23 patients studied. Remarkably, we found that Vespulaspecific $\operatorname{IgG}_{4}$ rose and then reached a plateau during the VIT course but declined substantially during the followup, since the $\mathrm{IgG}_{4}$ titres at 3 and 8 years follow-up timepoints are comparable to the ones observed before VIT (Fig. 3a).
This latter result suggests that long-term protection induced by VIT could be $\mathrm{IgG}_{4}$-independent. Interestingly, a previous report by Varga et al. [47] analysed the role of honeybee specific $\operatorname{IgG}_{4}$ in a group of 10 children that had undergone honeybee VIT. In line with our results, the authors of this study after a 2-year follow-up found no correlation between honeybee specific $\mathrm{IgG}_{4}$ levels and long-term efficacy of VIT.

In our study we evaluated, for the first time, Vespulaspecific $\mathrm{IgG}_{4}$ using two different technical approaches. In particular, the commercial kit for Vespula-specific $\operatorname{IgG}_{4}$ was based on the use of Vespula allergen pre-coated strips. In this assay, after the incubation with the patient serum, the presence of $\operatorname{IgG}_{4}$ is revealed using of anti-human $\operatorname{IgG}_{4}$-antibody conjugated with horseradish peroxidase. Nonetheless, in this experimental setting, the total amount of $\mathrm{IgG}_{4}$ revealed might be underestimated. Indeed, during the incubation, other Vespula-specific antibodies with different isotypes (e.g. $\operatorname{IgG}_{2}$, IgE), present in the patient serum, will most likely compete with $\mathrm{IgG}_{4}$ for the binding to the cognate antigen. In order to overcome this possible competition and to ascertain the results obtained with the commercial kit for Vespula-specific $\operatorname{IgG}_{4}$, we developed an in house-technique that we applied to six patients and nine normal controls. This assay relies on the use of precoated anti-IgG ${ }_{4}$ wells. After incubation with the patients' sera, Vespula-specific $\operatorname{IgG}_{4}$ are revealed using biotinylated Vespula allergen. Remarkably, the results obtained with the two distinct technique were comparable, thus validating our findings on $\mathrm{IgG}_{4}$ (Fig. 3b).

It has to be noticed that $\operatorname{IgG}_{4}$ titres at the beginning of the VIT were already higher compared to the 20 healthy controls, suggesting that in Hymenoptera venom allergic subjects an IgG-driven immune response already occurs independently from VIT. To our knowledge, this is the only study in which pre-VIT values of $\mathrm{IgG}_{4}$ in Vespula allergic patients are compared to those found in a group of normal adult individuals. Finally, we analysed the trend of the ratio between the Vespula-specific IgE and $\mathrm{IgG}_{4}$ over all the study period. Interestingly, this ratio progressively declines (from 70.1 to 27.2 , at the end of the VIT course). This decline appears to be even more pronounced at the end of the follow-up (14.2) (Additional file 4: Figure S1C). This latter result seems to corroborate the hypothesis that indeed Vespula venom VIT induces long-lasting immunological changes.

\section{Conclusions}

In conclusion, our results obtained in a relatively small but well-controlled cohort of patients (out of a series of 686 patients) show that Vespula VIT induces a robust and longlasting protection towards re-stinging events. The results obtained on Vespula-specific IgE levels show that IgE levels 


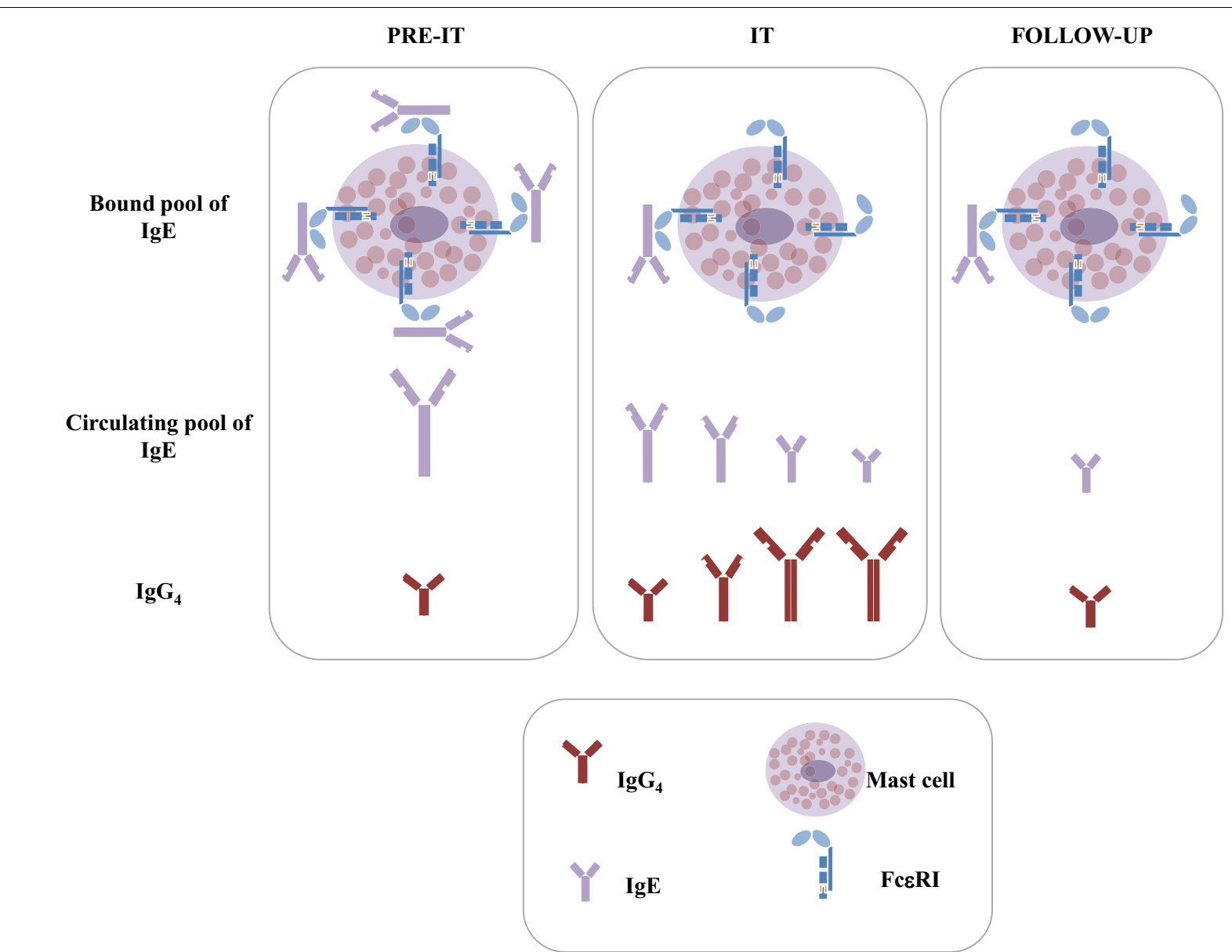

Fig. 4 Suggested model of long-lasting immunological changes induced by VIT. Before VIT, Vespula-specific lgE and lgG ${ }_{4}$ antibodies are already present in the patients. VIT induces a progressive and steady decline in both bound and circulating pools of lgE. In contrast, lg $\mathrm{G}_{4}$ levels increase. The IgE levels remain low long after VIT discontinuation, while the $\lg _{4}$ decline to pre-VIT values

(bound and unbound) closely match the VIT clinical efficacy. Particularly, IgE levels in the follow-up, are perhaps the best predictor of clinical efficacy of Vespula VIT. Furthermore, $\operatorname{IgG}_{4}$ levels were sustained during VIT course but declined substantially after the end of VIT and, therefore, are less useful in assessing clinical efficacy of VIT in the long term. Rather, specific $\operatorname{IgG}_{4}$ could be used as a signature of valid immune stimulation induced by VIT (Fig. 4).

\section{Additional files}

Additional file 1: Table S1. Comparative table of the existing reports on long-term clinical efficacy of VIT.

Additional file 2: Table S2. ALK-Abellò VIT protocol.

Additional file 3: Table S3. DHS VIT protocol.

Additional file 4: Figure S1. Kinetics of Vespula-specific lgE (A) and lgG4 (B) in response to DHS or ALK-Abellò VIT (C) Ratio between Vespula-specific lgE and lgG4 during VIT course and follow-up. Data in A and B were analised by ANOVA with Bonferroni post-test (n.s.>0.01).

\section{Abbreviations}

VIT: venom immunotherapy; RAST: radioallergosorbentest; OD: optical density; DHS: Dome-Hollister Stier; SQ-U: Standard Quality Unit.

\section{Authors' contributions}

MA analysed the data, wrote the manuscript, performed some of the $\lg _{4}$ work, helped with the project design and patient clinical assistance; AN helped with the analysis of the data and clinical assistance; LG performed the experiments with the help of MPR and MR, LM; AS, AR, GK and FL helped with the clinical assistance; MZ helped with analysis of the data; MFC discussed results, provided ideas, helped with the clinical and scientific work organization; DDB participated in the data analysis and provided critical reading of the manuscript; LM apart from clinical involvement, conceived and supervised the study, secured the financial support and revised the manuscript. All authors read and approved the final manuscript.

\section{Author details}

${ }^{1}$ School and Chair of Allergology and Clinical Immunology, Department of Emergency and Organ Transplantation, University of Bari-Aldo Moro, Piazza Giulio Cesare 13, Policlinico, 70124 Bari, Italy. ${ }^{2}$ Unit of Clinical Pathology, Policlinico di Bari, Piazza Giulio Cesare 13, Policlinico, 70124 Bari, Italy. ${ }^{3}$ School and Chair of Allergology and Clinical Immunology, Department of Medical and Surgical Sciences, University of Foggia, Via Luigi Pinto 1, 70100 Foggia, Italy. 


\section{Acknowledgements}

We are thankful to F. Frisenda and M. Di Giacomo from the University of BariAldo Moro for the help with the experimental work and to F. Joensson from the Antibody in Therapy and Pathology Laboratory, Institute Pasteur, Paris for providing critical reading of the manuscript.

\section{Competing interests}

The authors declare that they have no competing interests.

\section{Availability of data and materials}

All data will be made available upon request.

\section{Consent for publication}

Not applicable.

\section{Funding}

The authors declare that this study was carried out with institutional resources only.

\section{Ethics approval and consent to participate}

This study was approved by the ethical committee of "Ospedali Riuniti-Foggia", Via Luigi Pinto 1, 70100, Foggia. For all patients oral informed consent was obtained.

\section{Publisher's Note}

Springer Nature remains neutral with regard to jurisdictional claims in published maps and institutional affiliations.

Received: 20 September 2017 Accepted: 18 December 2017 Published online: 18 January 2018

\section{References}

1. Moffitt JE, et al. Stinging insect hypersensitivity: a practice parameter update. J Allergy Clin Immunol. 2004;114(4):869-86.

2. Bonifazi F, et al. Prevention and treatment of Hymenoptera venom allergy: guidelines for clinical practice. Allergy. 2005;60(12):1459-70.

3. Bilo BM, et al. Diagnosis of Hymenoptera venom allergy. Allergy. 2005;60(11):1339-49.

4. Keating MU, et al. Clinical and immunologic follow-up of patients who stop venom immunotherapy. J Allergy Clin Immunol. 1991;88(3):339-48.

5. Golden DB, et al. Discontinuing venom immunotherapy: outcome after five years. J Allergy Clin Immunol. 1996;97(2):579-87.

6. Golden DB, et al. Discontinuing venom immunotherapy: extended observations. J Allergy Clin Immunol. 1998;101(3):298-305.

7. Lerch E, Muller UR. Long-term protection after stopping venom immunotherapy: results of re-stings in 200 patients. J Allergy Clin Immunol. 1998;101(5):606-12.

8. Golden DB, et al. Outcomes of allergy to insect stings in children, with and without venom immunotherapy. N Engl J Med. 2004;351(7):668-74

9. Hafner T, DuBuske L, Kosnik M. Long-term efficacy of venom immunotherapy. Ann Allergy Asthma Immunol. 2008;100(2):162-5.

10. Reisman RE. Duration of venom immunotherapy: relationship to the severity of symptoms of initial insect sting anaphylaxis. J Allergy Clin Immunol. 1993;92(6):831-6.

11. Oka T, et al. Rapid desensitization induces internalization of antigen-specific IgE on mouse mast cells. J Allergy Clin Immunol. 2013;132(4):922932.e1-16.

12. Zhao D, et al. The functional lgE-blocking factor induced by allergen-specific immunotherapy correlates with lgG4 antibodies and a decrease of symptoms in house dust mite-allergic children. Int Arch Allergy Immunol. 2016;169(2):113-20

13. Gawlik R, et al. Effects of venom immunotherapy on serum level of CCL5/ RANTES in patients with Hymenoptera venom allergy. Immunopharmacol Immunotoxicol. 2015:37(4):375-9.

14. Cavkaytar O, Akdis CA, Akdis M. Modulation of immune responses by immunotherapy in allergic diseases. Curr Opin Pharmacol. 2014;17:30-7.
15. Bruhns $P$, et al. Specificity and affinity of human Fcgamma receptors and their polymorphic variants for human IgG subclasses. Blood. 2009;113(16):3716-25.

16. Vidarsson G, Dekkers G, Rispens T. IgG subclasses and allotypes: from structure to effector functions. Front Immunol. 2014:5:520.

17. van der Neut Kolfschoten M, et al. Anti-inflammatory activity of human IgG4 antibodies by dynamic Fab arm exchange. Science. 2007;317(5844):1554-7

18. Aalberse RC, Schuurman J. $\operatorname{lgG}_{4}$ breaking the rules. Immunology. 2002;105(1):9-19.

19. Müller UR. Insect sting allergy: clinical picture, diagnosis, and treatment. Stuttgart: Gustav-Fischer Verlag; 1990.

20. Patriarca $\mathrm{G}$ et al. Sublingual desensitization in patients with wasp venom allergy: preliminary results. Int J Immunopathol Pharmacol. 2008;21:669-77.

21. Corallino $M$, et al. Skin testing technique and precision in stinging insect allergy. J Clin Nurs. 2007;16(7):1256-64.

22. Macchia $L$, et al. Changes in skin reactivity, specific lgE and lgG levels after one year of immunotherapy in olive pollinosis. Allergy. 1991;46(6):410-8.

23. Jonsson F, Daeron M. Mast cells and company. Front Immunol. 2012:3:16.

24. Diane F, Jelinek I, James T. Immunoglobulin structure and functions. In: Franklin Adkinson N, Bochner B, Wesley Burks A, Holgate ST, Lemanske RF, editors. Middleton's, allergy. Elsevier Saunders; 2014. 1: p. Chapter 3:30-45.

25. Carr TF, Saltoun CA. Chapter 2: Skin testing in allergy. In: Allergy Asthma Proceedings. 2012. 33;1:S6-8.

26. Golden DB. Insect sting anaphylaxis. Immunol Allergy Clin N Am. 2007;27(2):261-72.

27. Randolph CC, Reisman RE. Evaluation of decline in serum venom-specific IgE as a criterion for stopping venom immunotherapy. J Allergy Clin Immunol. 1986:77(6):823-7.

28. Pravettoni $V$, et al. Determinants of venom-specific IgE antibody concentration during long-term wasp venom immunotherapy. Clin Mol Allergy. 2015;13:29.

29. Ginaldi L, et al. The immune system in the elderly: II. Specific cellular immunity. Immunol Res. 1999;20(2):109-15.

30. King TP, et al. Yellow jacket venom allergens, hyaluronidase and phospholipase: sequence similarity and antigenic cross-reactivity with their hornet and wasp homologs and possible implications for clinical allergy. J Allergy Clin Immunol. 1996:98(3):588-600.

31. King TP, et al. Protein allergens of white-faced hornet, yellow hornet, and yellow jacket venoms. Biochemistry. 1978;17(24):5165-74.

32. Frick $M$, et al. Predominant Api $m 10$ sensitization as risk factor for treatment failure in honey bee venom immunotherapy. J Allergy Clin Immunol. 2016;138(6):1663-71.

33. Blank $\mathrm{S}$, et al. Api m 10, a genuine A. mellifera venom allergen, is clinically relevant but underrepresented in therapeutic extracts. Allergy. 2011;66(10):1322-9.

34. Baker TW, et al. The HIT study: Hymenoptera Identification Test-how accurate are people at identifying stinging insects? Ann Allergy Asthma Immunol. 2014:113(3):267-70.

35. Golden DB, et al. Natural history of Hymenoptera venom sensitivity in adults. J Allergy Clin Immunol. 1997;100(6):760-6.

36. Durham SR, Till SJ. Immunologic changes associated with allergen immunotherapy. J Allergy Clin Immunol. 1998;102(2):157-64.

37. Wuthrich B, Arrendal H, Lanner A. Antibody response pattern (specific lgE and $\mathrm{lgG}$ ) of insect sting allergic patients in immunotherapy with venom preparations. Schweiz Med Wochenschr. 1981;111(46):1756-65.

38. Zuidscherwoude $M$, van Spriel AB. The origin of lgE memory and plasma cells. Cell Mol Immunol. 2012:9(5):373-4.

39. Wong KJ, et al. IgE+ B cells are scarce, but allergen-specific B cells with a memory phenotype circulate in patients with allergic rhinitis. Allergy. 2015;70(4):420-8

40. Pilette $C$, et al. Grass pollen immunotherapy induces an allergen-specific $\lg$ A2 antibody response associated with mucosal TGF-beta expression. J Immunol. 2007:178(7):4658-66.

41. Kerstan A, et al. Wasp venom immunotherapy induces activation and homing of CD4(+) CD25(+) forkhead box protein 3-positive regulatory $T$ cells controlling $\mathrm{T}(\mathrm{H}) 1$ responses. J Allergy Clin Immunol. 2011:127(2):495-501. 
42. Nouri-Aria KT, et al. Grass pollen immunotherapy induces mucosal and peripheral IL-10 responses and blocking IgG activity. J Immunol. 2004;172(5):3252-9.

43. Ozdemir C, et al. Mechanisms of immunotherapy to wasp and bee venom. Clin Exp Allergy. 2011;41(9):1226-34.

44. Adjobimey T, Hoerauf A. Induction of immunoglobulin G4 in human filariasis: an indicator of immunoregulation. Ann Trop Med Parasitol. 2010;104(6):455-64.
45. Akdis CA, Akdis M. Mechanisms of allergen-specific immunotherapy and immune tolerance to allergens. World Allergy Organ J. 2015;8(1):17.

46. Akdis $\mathrm{M}$, Akdis CA. Mechanisms of allergen-specific immunotherapy: multiple suppressor factors at work in immune tolerance to allergens. J Allergy Clin Immunol. 2014;133(3):621-31.

47. Varga EM, et al. Time course of serum inhibitory activity for facilitated allergen-IgE binding during bee venom immunotherapy in children. Clin Exp Allergy. 2009;39(9):1353-7.

\section{Submit your next manuscript to BioMed Central and we will help you at every step:}

- We accept pre-submission inquiries

- Our selector tool helps you to find the most relevant journal

- We provide round the clock customer support

- Convenient online submission

- Thorough peer review

- Inclusion in PubMed and all major indexing services

- Maximum visibility for your research

Submit your manuscript at

www.biomedcentral.com/submit 